\title{
Illinois Accelerator \\ Research Center (IARC)
}

ICARST 2017 of Radiation Science and Technology
1 st International Conference on Applications


Dr. Charlie Cooper

General Manager of IARC at

Fermi National Accelerator Lab

ICARST 2017, Vienna, Austria

Wednesday April 26th, 16:30-18:30

\section{贲 Fermilab}

50 Years of Discovery 


\section{Fermi National Accelerator Lab}



- Fermi is a National Lab Funded by the Department of Energy

- $\sim 360 \mathrm{M} / \mathrm{yr}$ operating budget with 1700 staff (>2000 users)

- Base mission of discovery science through high energy physics research

- Celebrating 50 years of science(Discovery of Top Quark, Bottom Quark, Observation Tau Neutrino)

- Fundamental discovery tool at Fermi is the particle accelerator

- Largest concentration of accelerator experts in the World

- Expertise in accelerator design, simulation, fabrication, integration and test

Unique facilities for design, test and operation of accelerators 


\section{Illinois Accelerator Research Center}

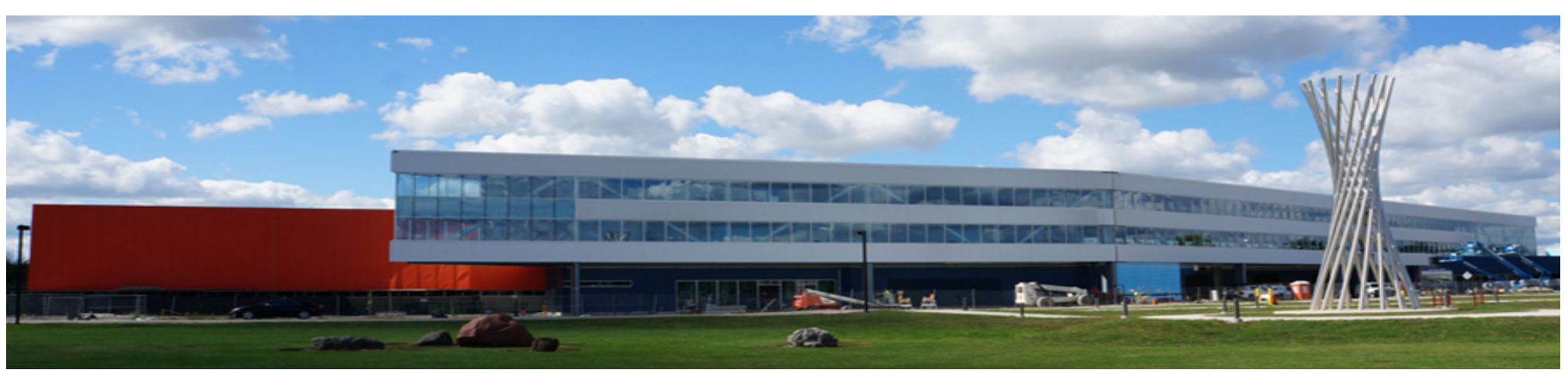

- There have been and will continue to be new technologies developed in the pursuit of basic science. (Accelerators, Detectors, Magnets, Computing)

- IARC is focused on developing accelerator based technologies to the point where they are attractive to industry.

- Through IARC we can leverage Fermi's human capital, facilities and technologies.

- We believe that the technologies we are developing at IARC will enable new fields and demonstrate Fermi's impact, beyond basic discovery science, on the nation's health, security and wealth.

\section{http://iarc.fnal.gov/}

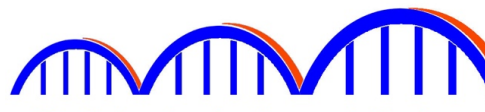


- Accelerator Science

\section{Fermi's Expertise}

- Beam dynamics, Simulation and Modeling

Phase-space manipulation, Energy Deposition

- Accelerator Operation

- Accelerator Technology

- Particle sources, targets, superconducting RF cavities and cryomodules, conventional magnets, superconducting magnets , cryogenic systems, high and low level RF systems, controls and DAO and beam cooling and beam instrumnetation

Detectors/Computing

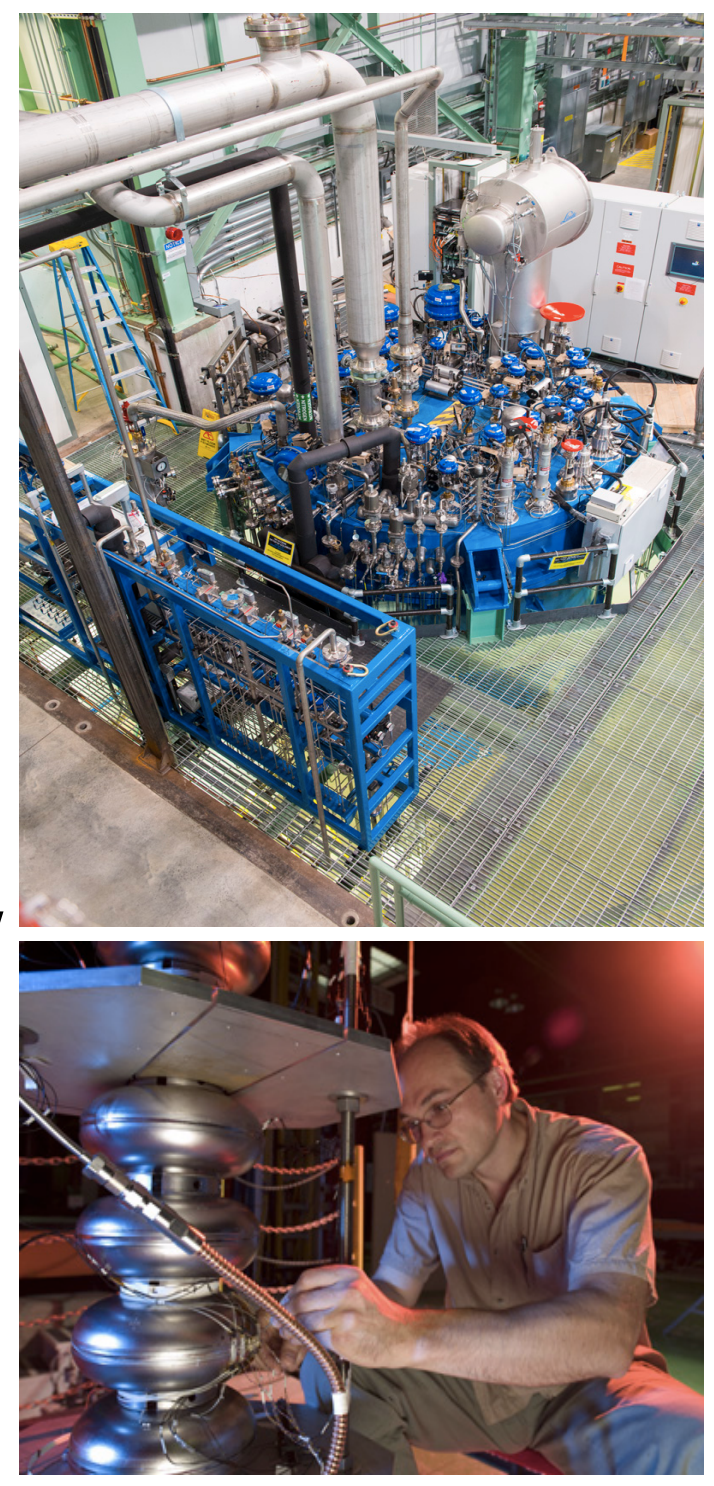




\section{Facilities Accessible Through IARC}

- IARC Core Facilities

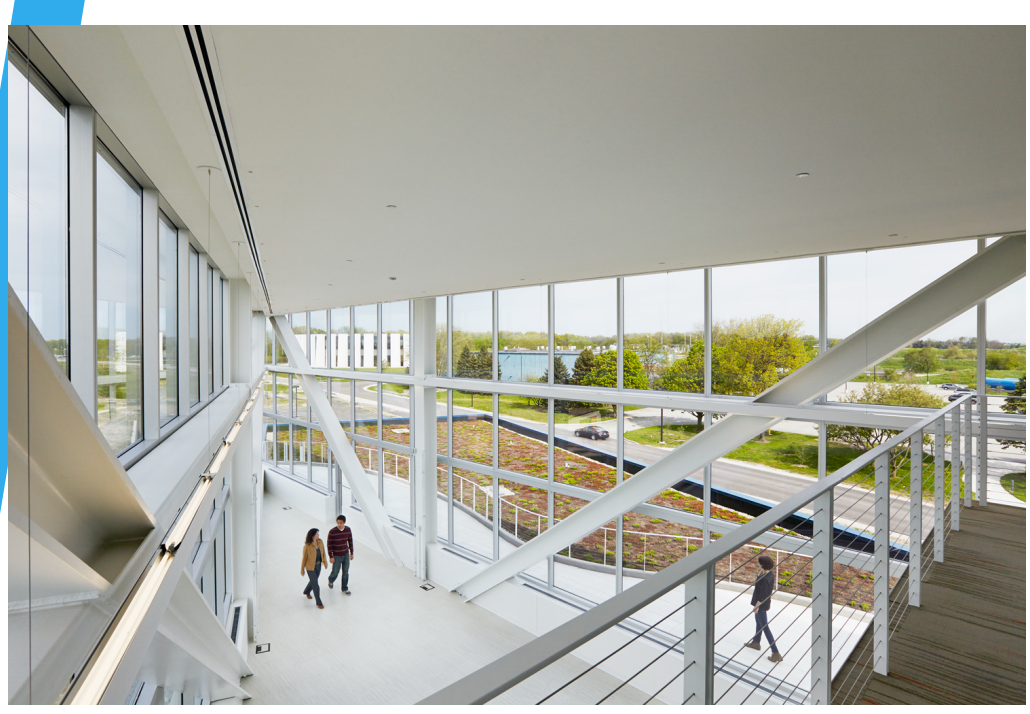

Office Technology and

Engineering Building

- 47,000 square feet

- 110 work spaces

- 175 person conference hall

- Light tech space Inside and outside eating area

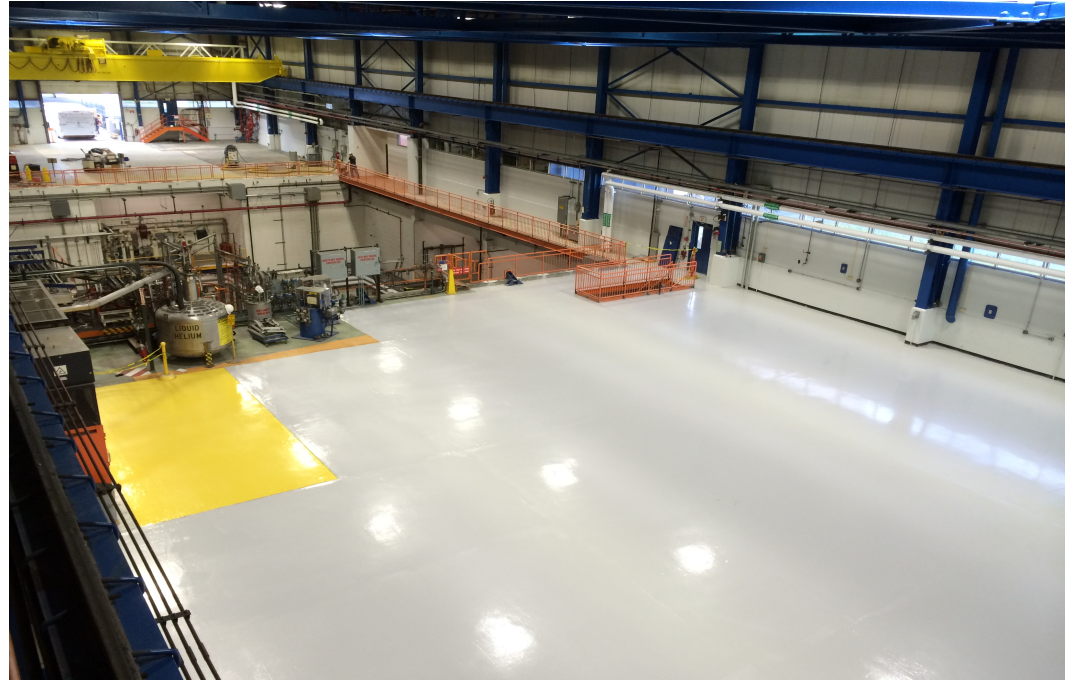

Heavy Assembly Building

- Repurposed Collider Detector Facility

- 42,000 sq ft

- 50 T crane, 10 T crane

- Radiation shielding

- 1.5 MW of Power2.0 MW of chilled water

-60oW @4 K cryogenic refrigerator

- 2 developmental accelerators 


\section{Facilities Accessible Through IARC}

- Repurposed Industrial Accelerator

- 4-22 MeV, $3 \mathrm{~kW}$

- Radiabeam ARCIS Acceler. (Cargo Scanning)

- 2-9 MeV, $58 \mathrm{~kW}$

- Infrastructure for Accelerator \& Subcomponent Design, Manufacture and Test

- http://iarc.fnal.gov/pilot/files/FermilabAcceler

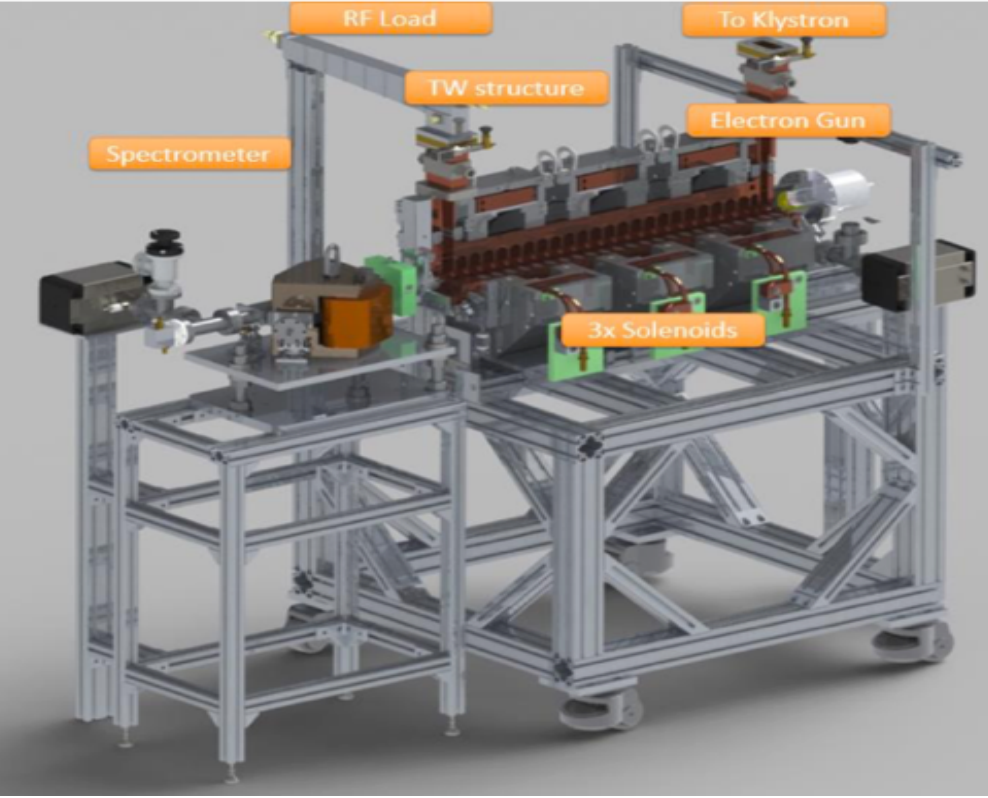
atorCapabilities-print.pdf
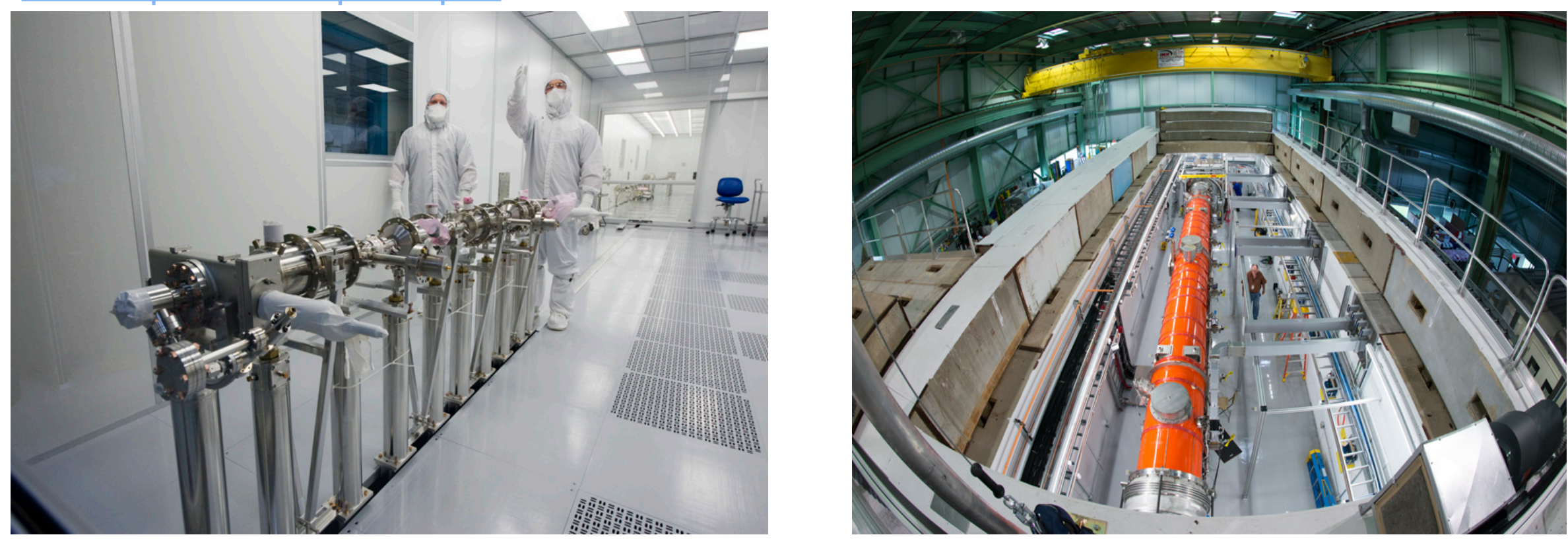


\section{Technology Maturation}

Compact Accelerator Platform Technology

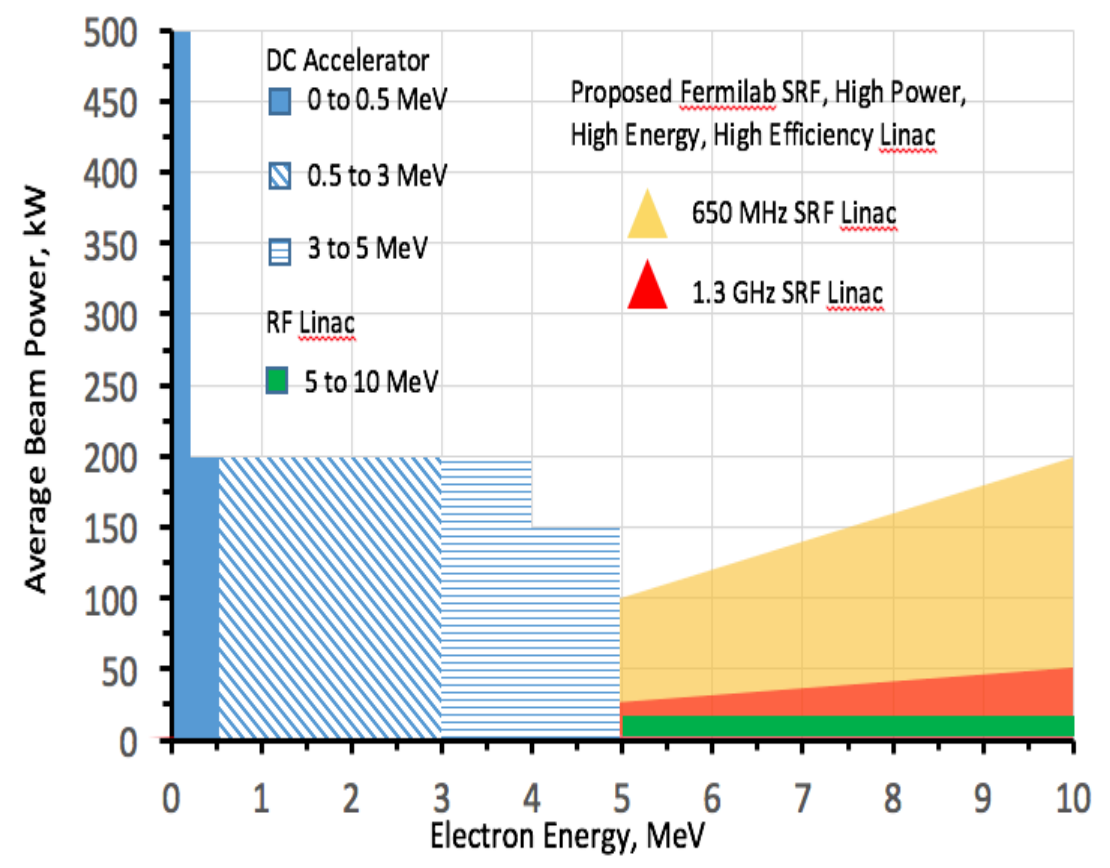

- Currently we are integrating multiple new technologies to create a compact, portable, high power electron beam platform accelerator.

- In design phase

- Build and test first article in 4 year time frame.

- Tom Kroc will detail

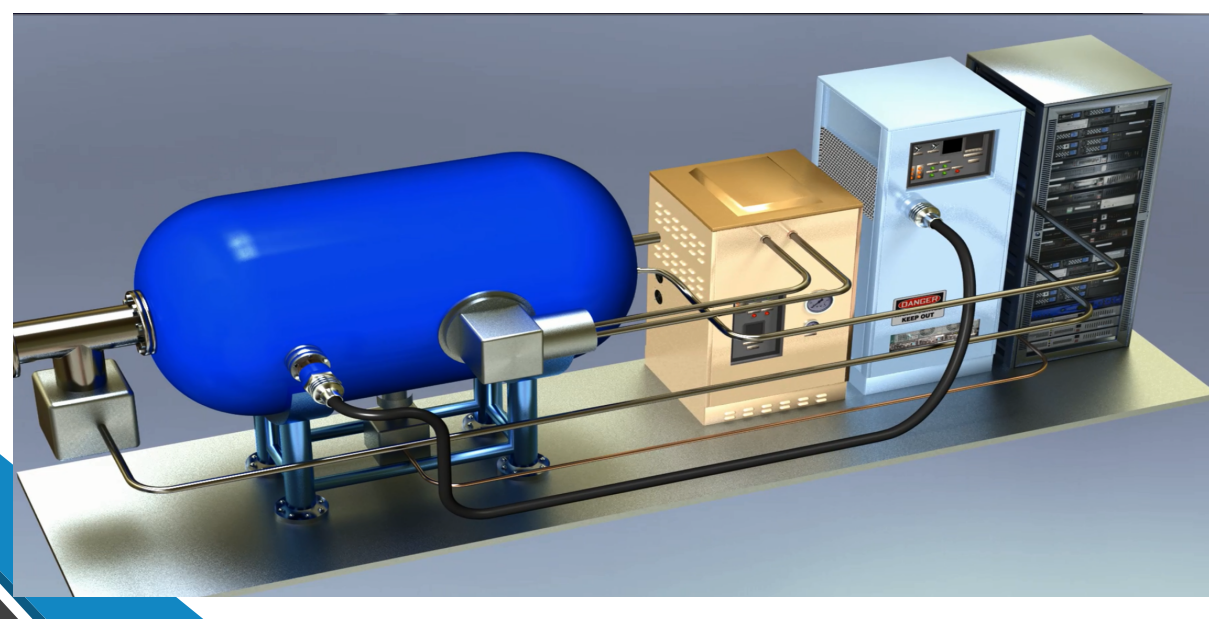
compact accelerator (A1003)

- We are concurrently developing applications for this compact accelerator. 


\section{Application Areas}

- Water/Biosolids

- Cargo Scanning

- Modification of Materials (like pavement)

- Medical Sterilization

- Driving various industrial chemistries

- GTL of flare gas

- Rubber
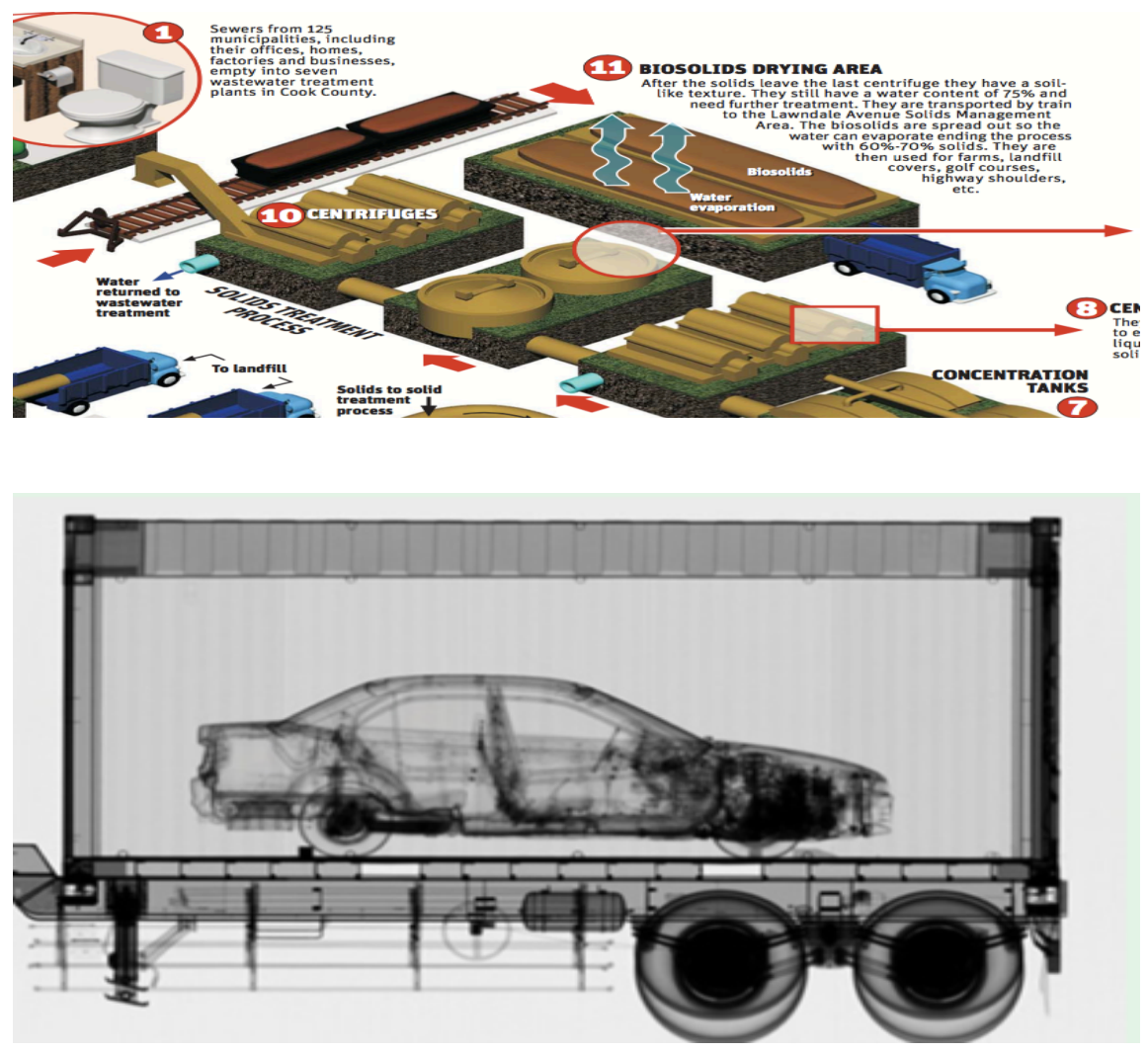

- Environmental remediation, Advanced Mnfg, food treatment, surface hardening, digital electronics, mining

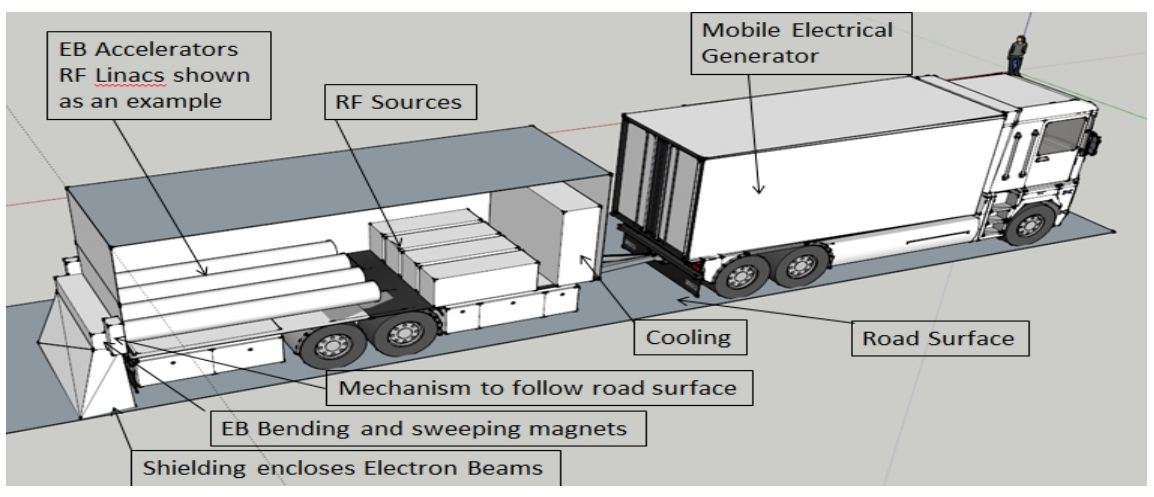




\section{Municipal Water Treatment via Compact Accelerator}

- Currently partnered with Metropolitan Water Reclamation District of Chicago

- Stickney plant, largest in the world (1.2 Billion gal/day)

- Incoming water is a fuel source not just waste

- Goal of net zero energy operation

- Desire to recover nitrates and phosphates



- Biosolids can be sold as fertilizer 


\section{Accelerators for National Security}
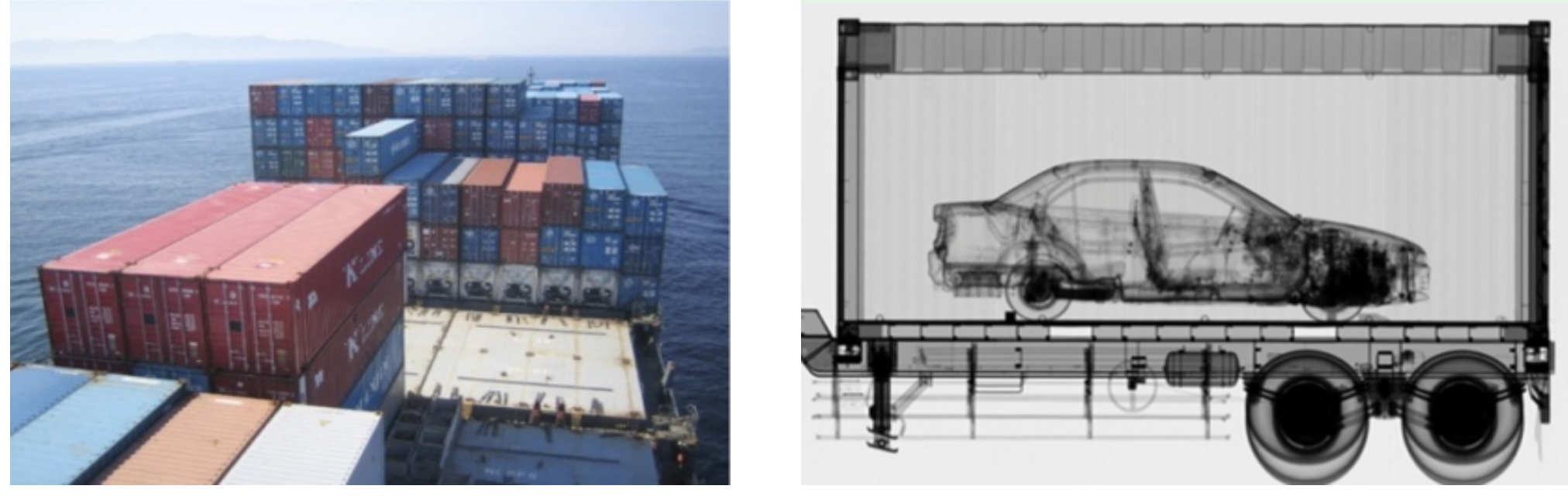

- Cargo scanning and "active interrogation" to detect special materials

- Typically employ $x$-ray tubes or electron beam accelerators

- Electron beam sources with energies 6-g MeV are needed

- Typically based on copper Radio-Frequency (RF) Accelerating

Structures first developed in the 1960's (pulsed)

- Needs: Continuous Wave (CW) operation, higher beam power, lighter and more efficient: for mobile applications 


\section{Compact Accelerator for Pavement}

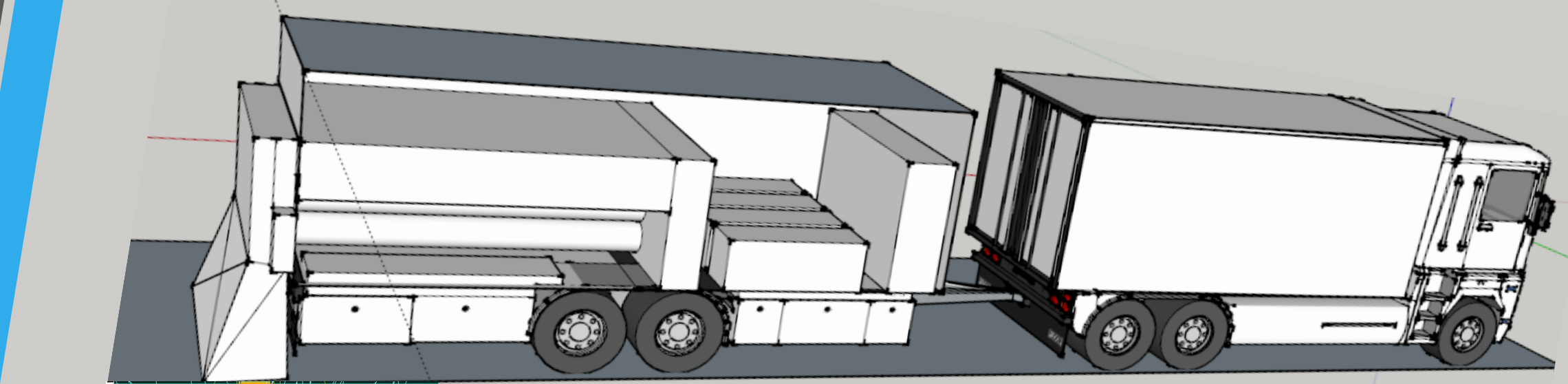

- High power and good penetration depth allow for rapid deployment of new pavement

- Enables use of new types of pavement materials that are more resilient to wear than asphalt

- Can be used for applications like military runways, specialty coatings, and normal roadways

- Penetration depth allows for cold repairs

- Patent \# 


\section{Radiological Security}

- Radioactive sources are used for cancer treatment, food \& blood sterilization, oil exploration, radiography, and scientific research. They contain isotopes that could be used to make a radiological dirty bomb.

RADIATION излучение

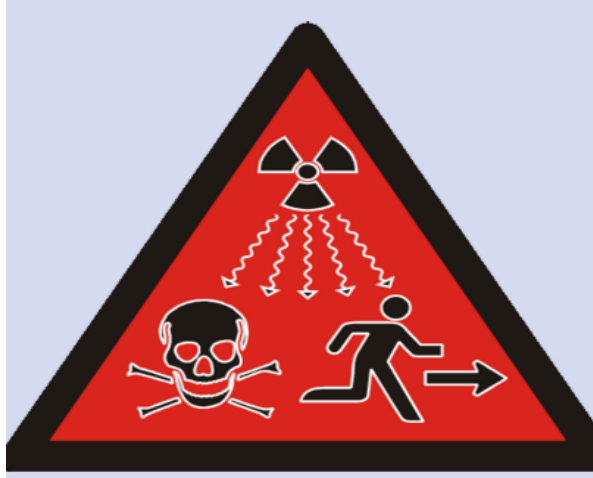

- "NNSA is working to remove or secure significant quantities of excess, vulnerable radiological materials that exist worldwide and could be used to make a dirty bomb."

- Recent technological advances within the DOE Office of Science allow us to envision accelerator based replacements that will be inherently safe against such misuse

- When an EB accelerator is switched "off " it produces NO radiation. It can't be used to create a radiological dirty bomb. 


\section{Compact Accelerator for Environmental Remediation}

- In several pilot programs electron accelerators have be proven to be effective at destroying toxic organic contaminates in water and soil

- Typically large volumes of material are removed from contaminated areas creating a concern of secondary contamination

- Key to deployment at large scale is development of high power (100's of $\mathrm{KW}$ to MW class) industrial electron accelerators that are cost effective and reliable

- Compact Accelerator could enable new in-situ environmental remediation or decontamination processes

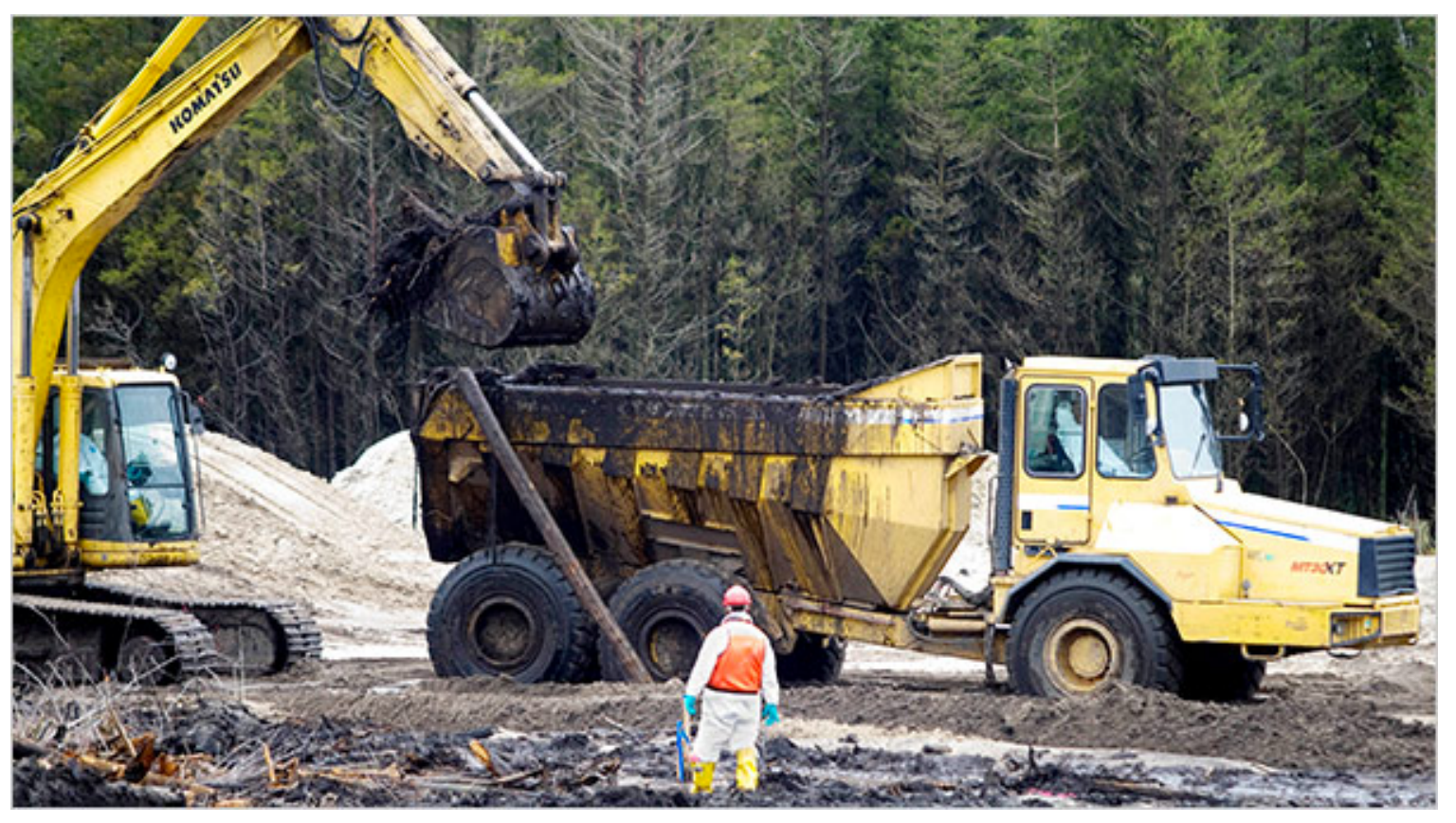




\section{Compact Accelerator for Crops}

E-Beam treatment can improve shelf life, destroy disease causing bacteria and be used for pest control

- A portable high power accelerator has the potential for saving crops in quarantined areas

- E-Beam treatment can improve shelf life, destroy disease causing bacteria and be used for pest control
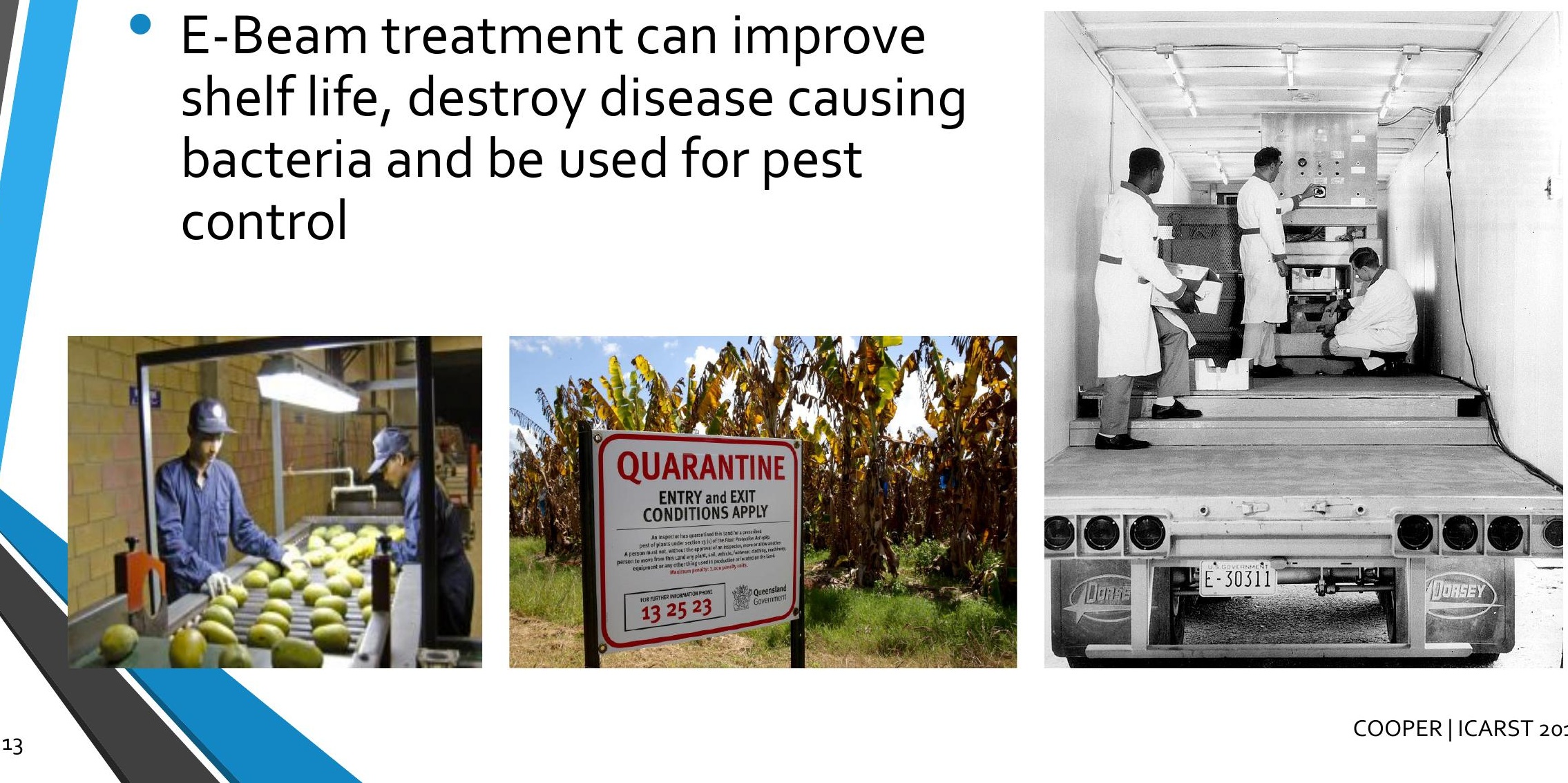


\section{Compact Accelerator for Driving Chemistry}

- In the U.S. Industry consumes $\sim 32 \%$ of end use sector

- $27 \%$ of that is used in the Chemical Sector (www.eia.gov)

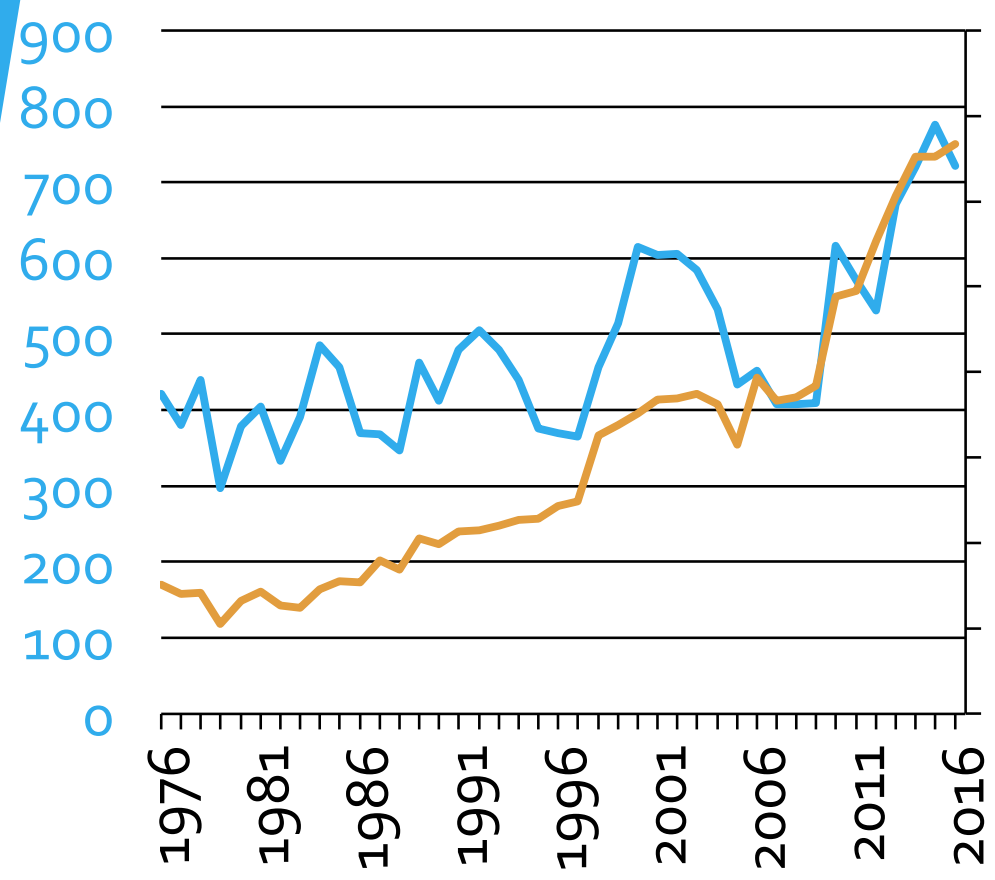

Total \# US Original Catalyst Patents Total \# US Original Patents patft.uspto.gov
- Demonstrated industrial effort to develop catalyst to increase efficiency

- Electron Beam Driven Chemistry largely unexplored

- More efficient that direct heating

- Rubber Industry

- Can remove need for some toxic initiators, cross linkers

- Can control residence time of reaction

- Currently investigating pooled research model 


\section{Questions}


- Please use a PowerPoint format for your presentation. The length should be maximum one slide per minute, i.e. if you have 15 minutes for your presentation, you should not have more than 15 slides please. Use font size bigger than 20 and please place the conference logo on your slides (the logo is attached).

- Send you presentation at ICARST-2017.Contact-Point@iaea.org as soon as possible and no later than 15 April 2017. We need sufficient time to go over all the presentations for the conference and ensure they meet the guidelines for this event.

- Also please sign the attached form for releasing your presentation on our website and send it back as soon as possible and no later than 15 April 2017 to us. 